\title{
CORRESPONDENCE
}

\section{MISTER or DOCTOR}

To the Editors of THE BRITISH JouRnal of OpHTHALMOLOGy.

DEAR SIRS, - Although strictly speaking the title of Doctor should be confined to those who are "Doctors," i.e. those who hold the degree of Doctor of a University, yet since this title is now so universally applied to any duly qualified medical practitioner I agree with the writer of the annotation on the above subject that it is questionable whether this "Mister - Doctor" distinction subserves any useful purpose now, although it may have done in the past in the days when the Surgeon was a sort of "plumber" called in by the Physician to do a piece of technical manual work.

As I see it the chief disadvantages of the use of the term "Mister" as applied to a Surgeon are :-

1 . It is confusing to the lay public.

2. It is confusing to our medical colleagues in other countries.

3. It " covers" the "unqualified" medical practitioner, for how can the layman easily distinguish (if he wishes to do so) between two gentlemen with West End addresses in the Medical area, one being a reputable Surgeon medically qualified, the other being a notmedically-qualified "naturopath," both styling themselves "Mister"?

Similarly how can the layman easily distinguish between a medically qualified ophthalmologist and an optical practitioner or ophthalmic optician, if both are just " Mister."

Now that we are on the eve of the establishment of a State Medical Service in which it is envisaged that sight testing opticians will take their official place, I would advocate that the medical men in the ophthalmic profession should for the sake of differentiation style themselves Doctor instead of Mister (just as they do in Scotland and also in Manchester).

I might add that I have no personal feelings on the subject and could not care less whether I am addressed as Mister, Doctor or just

Yours truly,

KEITH LYLE.

42, Charles Street, W.1.

30th January, 1947.

MEPACRIN AND THE EYE

To the Editors of The BRitish Journal of OpHThaLMology.

DeAR Sirs,--Miss Ida Mann in her communication "Blue Haloes in Atebrin Workers" has solved the clinical appearance of what 
was at one time a diagnostic problem among African troops in India. The self-inflicted ocular injury caused by putting powdered mepacrin in the conjunctival sac. Although it was by that time well recognised, the first case I saw was shown to me in the summer of 1945 by Major A. E. Wilson, Ophthalmic Specialist of 135 West African General Hospital. His very accurate description of this case is as follows. "The bulbar conjunctiva was stained in an area surrounding the limbus and extending laterally in an area corresponding with the palpebral fissure. The bulbar conjunctiva above and below were devoid of any staining and the lines of demarcation above and below were sharp. The palpebrae were clear apart from narrow bands at the posterior aspects of the lid margins. The cornea was hazy and had a yellow-green colouration as if fluourescein had been inserted into the conjunctival sac and had been incompletely washed out.". Major Wilson had already made the diagnosis and having searched the soldier's kit had found a yellow powder which proved to be mepacrin. He later removed a portion of the affected conjunctiva and on chemical test it gave a positive test for mepacrin. The yellow staining in the cornea disappeared after, I think, some weeks. A rumber of these cases were seen both by Major Wilson and by Major Hollingsworth (40 West African General Hospital) among African troops. Both these specialists reported that there was a mild conjunctivitis in the early stages and that in some a striate keratitis was present. No haloes were complained of as far as I know.

One of the diagnostic difficulties in these cases was the fact that although the mepacrin powder was presumably put in the lower fornix the conjunctival staining, with its definite edges, was limited to the interpalpebral zone of the bulbar conjunctiva. Thus it appears that exposure, possibly associated with oxygen intake. may play an essential part in the ability of the cells to take up the staining granules. The narrow yellow line on the conjunctiva of the lower lid margin was very noticeable and not easily explained either. The "striate keratitis" noticed in some cases is no doubt the same as the corneal oedema produced by massive local application in Miss Mann's experiments.

As a self-inflicted injury this procedure was successful for in a country with a high incidence of jaundice some delay was inevitable before the diagnosis could be established, thus affording the soldier the change and rest that he desired.

Yours truly,

2, FitzWilliam PLACE,

L. B. SOMERVILle-LARGE. DUBLIN.

January 28, 1947. 